\title{
Static Eccentricity Fault Recognition in Three-Phase Line Start Permanent Magnet Synchronous Motor Using Finite Element Method
}

\author{
Mahdi Karami, ${ }^{1,2}$ Norman Mariun, ${ }^{1,2}$ Mohammad Rezazadeh Mehrjou,,2 \\ Mohd Zainal Abidin Ab Kadir, ${ }^{2}$ Norhisam Misron, ${ }^{2}$ and Mohd Amran Mohd Radzi ${ }^{1,2}$ \\ ${ }^{1}$ Centre for Advanced Power and Energy Research, Faculty of Engineering, Universiti Putra Malaysia, \\ 43400 Serdang, Selangor, Malaysia \\ ${ }^{2}$ Department of Electrical and Electronic Engineering, Faculty of Engineering, Universiti Putra Malaysia, \\ 43400 Serdang, Selangor, Malaysia \\ Correspondence should be addressed to Mahdi Karami; karami.mahdi399@gmail.com
}

Received 15 July 2014; Revised 22 October 2014; Accepted 5 November 2014; Published 24 November 2014

Academic Editor: Yang Tang

Copyright (C) 2014 Mahdi Karami et al. This is an open access article distributed under the Creative Commons Attribution License, which permits unrestricted use, distribution, and reproduction in any medium, provided the original work is properly cited.

\begin{abstract}
This paper is dedicated to investigating static eccentricity in a three-phase LSPMSM. The modeling of LSPMSM with static eccentricity between stator and rotor is developed using finite element method (FEM). The analytical expression for the permeance and flux components of nonuniform air-gap due to static eccentricity fault is discussed. Various indexes for static eccentricity detection using stator current signal of IM and permanent magnet synchronous motor (PMSM) are presented. Since LSPMSM is composed of a rotor which is a combination of these two motors, the ability of these features is evaluated for static eccentricity diagnosis in LSPMSM. The simulated stator current signal of LSPMSM in the presence of static eccentricity is analyzed in frequency domain using power spectral density (PSD). It is demonstrated that static eccentricity fault generates a series of low frequency harmonic components in the form of sidebands around the fundamental frequency. Moreover, the amplitudes of these components increase in proportion to the fault severity. According to the mentioned observations, an accurate frequency pattern is specified for static eccentricity detection in three-phase LSPMSM.
\end{abstract}

\section{Introduction}

Energy economizing is a crucial object that leads the world to conservation and preventive policy against the shortage of resources as well as environmental pollution and global warming. Electrical energy consumes great portion of resources owing to new developments in industries, growth of population, and changing of the human needs [1]. As it is reported, the electrical motors use up to $50 \%-60 \%$ of electric energy in different applications $[2,3]$ and induction motors (IMs) are expending 96\% from this part of energy only in United States [3]. Accordingly, the idea of replacing IMs with higher efficiency electrical motors is seriously being considered. Hitherto, the permanent magnet synchronous motor (PMSM) could be an option for substitution of IM due to higher efficiency and admissible production cost.
The principal drawback of PMSMs is their inverter-fed characteristic that makes them uneconomic motors since $70 \%-80 \%$ of electrical motors applications pertain to the constant-speed performance [3].

The cage equipped permanent magnet motor known as LSPMSM has been introduced as the high efficiency motor with high starting capability with no need of drive system $[3,4]$. The LSPMSM is launched commercially in the recent years and recommended as a suitable alternative to IMs [5]. The structure of LSPMSM comprises a single- or three-phase stator similar to IM and a hybrid rotor containing conductor bars and permanent magnets. Figure 1 depicts the crosssection of one pole of a three-phase LSPMSM. The rotor bar produces the starting torque due to the fact that the induction current in the bars establishes an electromagnetic field, which interacts with the rotatory field and subsequently 

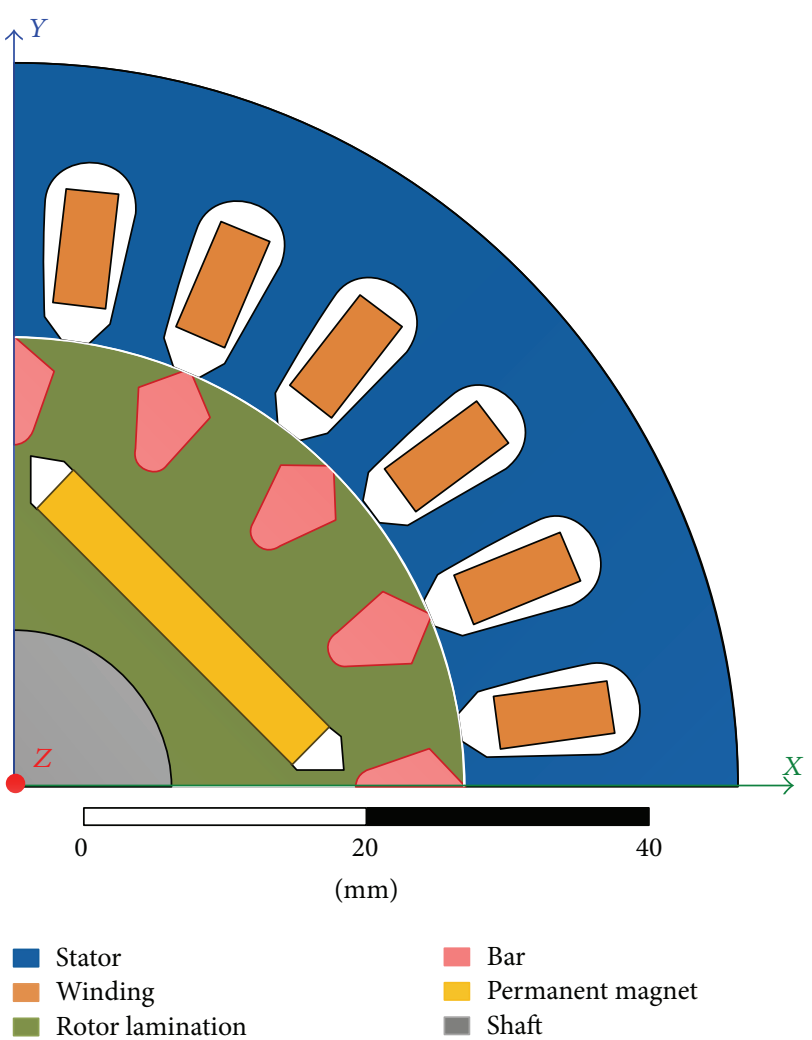

FIGURE 1: The cross-section of three-phase LSPMSM.

pulls the motor toward the synchronism. Despite the induced current, the copper loss in the bars is negligible because of the synchronous operation. On the other hand, the permanent magnets of rotor produce the synchronous torque at steady state. Besides, the permanent magnets generate an opposing torque at the starting status which diminishes by designing the high-deepness rotor slots $[3,6]$.

Despite the superior advantages of LSPMSM, the fault occurrence due to various stresses and operation conditions is unavoidable. It has been deduced from previous studies that the mechanical faults are prevalent failures in electrical motors as they represent up to $60 \%$ among all types of failures. Eccentricity fault constitutes $80 \%$ of mechanical faults and is considered as a critical failure in electrical motors $[7,8]$. The eccentricity fault is generally defined as the nonuniform air-gap distribution between the stator and rotor due to displacement of one or all the rotor symmetry axis, stator symmetry axis, and rotor rotation axis from their origin, which are classified as static, dynamic, and mixed eccentricity [9]. Hitherto, numerous research efforts have been dedicated to eccentricity fault diagnosis in IMs, PMSMs, and other types of electrical machines; yet, the LSPMSM is not taken seriously.

The winding function method (WFM) is introduced for modeling and simulation of electrical motors in order to evaluate their dynamic performance at healthy condition and under internal faults such as eccentricity between stator and rotor [10-13]. Nevertheless, other simulation studies are focused on finite element method for modeling of electrical motors [14, 15]. This method provides accurate and inexpensive technique for analyzing electrical motors. Finite element method also takes into account the material characteristic, nonlinearity, and complex structures of motor. Therefore, this technique provides a precise modeling tool to investigate the behavior of electrical motors. In case a motor operates under faulty condition, some unexpected phenomenon comes up, which is more accurate to apply finite element method rather than other approaches such as WFM $[10,14]$.

Different signals of electrical motors can be generated using finite element method such as stator current, torque, speed, and magnetic flux. The stator current is the prevalent monitored signal of motor for fault detection based on its accessibility and inexpensive measurement device [16, 17]. Each fault generates particular harmonic components in the stator current spectra in which extracting these features is referring to the specific fault in the motor $[18,19]$. Several indexes have been proposed for eccentricity fault detection in different types of electrical motors such as $[7,20-22]$ in IM and $[23,24]$ in PMSM. It must be noted that the type of electrical motors has significant influence on fault detection based on their different structures $[25,26]$.

Recall that there is not any scientific manuscript or published results related to eccentricity fault in LSPMSM. Hence, the first and important part of study on eccentricity fault in LSPMSM is to identify the features for eccentricity fault detection. In this paper, performance of LSPMSM under static eccentricity during steady state operation is scrutinized employing finite element method. The stator line current is used for a comprehensive study to evaluate the ability of these features for static eccentricity detection.

\section{The Concept of Static Eccentricity Fault in Electrical Motor}

Normally, the rotor that is centered at the stator bore of healthy motor results in identical air-gap among the stator and rotor. Accordingly, the magnetic forces are balanced in the opposite directions, but when the eccentricity emerges, this air-gap lessens on one side whereas it increases on the other side at any gyration angle which causes higher absorption force through the shorter gap $[9,27]$.

Static eccentricity in electrical motors occurs when the rotor symmetrical axis is concentric with the rotor rotational axis; however they are dislocated with respect to the stator symmetrical axis; hence, the position of minimum radial air-gap length is fixed $[28,29]$. In this situation the mutual inductances across the stator and rotor as well as the self- and mutual inductances between the rotor phases are a function of rotor angular position. The self- and mutual inductances among the stator phases are invariant and independent of the rotor angular position, same as healthy condition of motor [10]. The implication of static eccentricity fault in motor is depicted in Figure 2.

The static eccentricity can be due to numerous motives such as elliptical stator core, wrong placement of the rotor or 


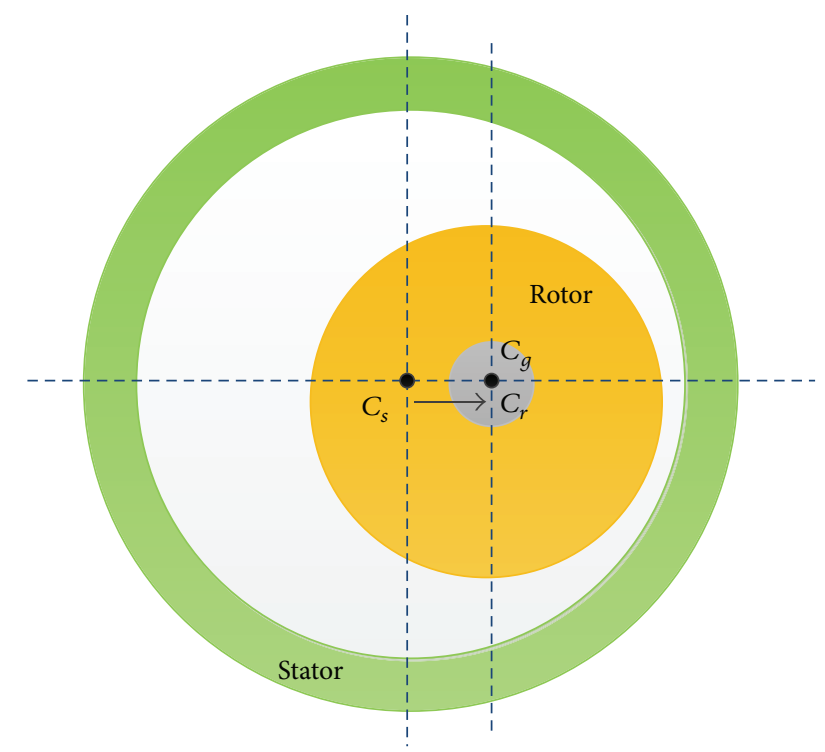

FIGURE 2: Cross-section of motor under static eccentricity: $C_{s}$ is the center of stator; $C_{r}$ is the center of rotor; and $C_{g}$ is the center of rotation.

stator at the setup or subsequent to maintenance, incorrect bearing positioning, bearing deterioration, shaft deflection, housings imperfection, end-shield misalignment, excessive tolerance, rotor weight, or pressure of interlocking ribbon [30-32]. Accordingly, the static eccentricity leads to second failures which results in drastic harm to the rotor, stator core, and windings. The radial forces in static eccentricity condition produce a steady unbalanced magnetic pull (UMP) in the radial route across the motor [33] due to the fact that the reluctance of the magnetic flux path decreases versus the transmission of flux on the side of tiny air-gap. However, the winding current induces more magnetic flux that causes the stronger pull and leads to expanding the air-gap on the opposite side where the reluctance increases; thus the flux and magnetic side pull decrease. Therefore, the UMP compels the rotor to move toward the area of the narrowest airgap length until the abrasion of the stator core subsequently generates abnormal vibration and severe damage to the rotor, the windings, and the stator [27]. Consequently, the static eccentricity causes acoustic noise, premature failure in the bearing, rotor deflection, and bent rotor shaft.

\section{Static Eccentricity Detection Scheme}

Different indexes have been recommended for static eccentricity fault detection in electrical motors and the efficiency of faulty motor has been analyzed via various methods. LSPMSM under eccentricity fault has not been investigated yet and thus no feature is available for eccentricity detection in this motor. In order to extract a reliable feature for static eccentricity fault detection in LSPMSM, the monitored signal should be processed by appropriate harmonic analysis. However, since LSPMSM is a hybrid motor of IM and PMSM, this study first examines the reliability of features extracted from stationary stator current for static eccentricity detection in IMs and PMSMs. The analytical studies of IM and PMSM with static air-gap eccentricity are expressed in the following portions.

3.1. The Analytical Theory of Static Eccentricity in IM. The occurrence of static eccentricity fault leads to an asymmetric air-gap where the magnetomotive force (MMF) of stator shapes this air-gap by permeance harmonics into the electromotive force (EMF) induced in the rotor. The same process follows for EMF which is induced in the stator based on the rotor MMF [34]. So, the magnetic flux in the air-gap is the product of permeance and MMF that forms a complex field in the air-gap containing various components such as fundamental components, stator and rotor MMF harmonics, stator and rotor slot permeance harmonics, eccentricity permeance harmonics, and permeance harmonics because of saturation. The computation style of air-gap field which demonstrates the flux density distribution in the air-gap is shown in Figure 3 [35]. On the basis of transforming the stator/rotor frame of reference, the MMF due to motor phase current in the healthy IM can be written as [22]

$$
F_{s}=A \cos \left(p_{n} x \pm \omega t\right)
$$

where $p$ is the number of main pole pairs, $n$ is the number of spatial harmonics, $x$ is angular position, $A$ is an integer value, $\omega$ is angular supply frequency ( $\mathrm{rad} / \mathrm{sec})$, and $t$ is time variable (sec). The analysis is followed supposing no slotting effect as well as saturation.

The permeance of a smooth air-gap machine in healthy condition can be approximately represented as

$$
P \approx P_{0},
$$

where $P_{0}$ is the average part of permeance function.

The air-gap flux components generated by MMF and permeance with respect to stator $\left(\Phi_{g s_{1}}\right)$ and rotor $\left(\Phi_{g r_{1}}\right)$ are defined as

$$
\begin{gathered}
\Phi_{g s_{1}}=A P_{0} \cos \left(p_{n} x \pm \omega t\right), \\
\Phi_{g r_{1}}=A P_{0} \cos \left[\left(p_{n} x^{\prime}+\omega_{r} t\right) \pm \omega t\right],
\end{gathered}
$$

where $x^{\prime}$ is the angular position of rotor and $\omega_{r}$ is rotor rotational speed $(\mathrm{rad} / \mathrm{sec})$.

Afterwards, these components bring subsequent pole pair rotor MMF harmonics $[22,36]$ with the content of $R \pm p_{n}$, which interact with $P_{0}$ and yield the following types of air-gap flux components regarding stator $\left(\Phi_{g s_{2}}\right)$ and rotor $\left(\Phi_{g r_{2}}\right)$ :

$$
\begin{gathered}
\Phi_{g s_{2}}=A_{1} P_{0}^{2} \cos \left[\left(R \pm p_{n}\right)\left(x-\omega_{r} t\right) \pm p_{n} \omega_{r} t \pm \omega t-\emptyset_{1}\right] \\
\Phi_{g r_{2}}=A_{1} P_{0}^{2} \cos \left[\left(R \pm p_{n}\right) x^{\prime} \pm p_{n} \omega_{r} t \pm \omega t-\emptyset_{1}\right] .
\end{gathered}
$$

Whereas $\omega_{r}=[(1-s) / p] \omega$ in $(\mathrm{rad} / \mathrm{sec})$,

$$
\Phi_{g s_{2}}=A_{1} P_{0}^{2} \cos \left[\left(R \pm p_{n}\right) x-\left\{R \frac{(1-s)}{p} \pm 1\right\} \omega t-\emptyset_{1}\right] \text {. }
$$




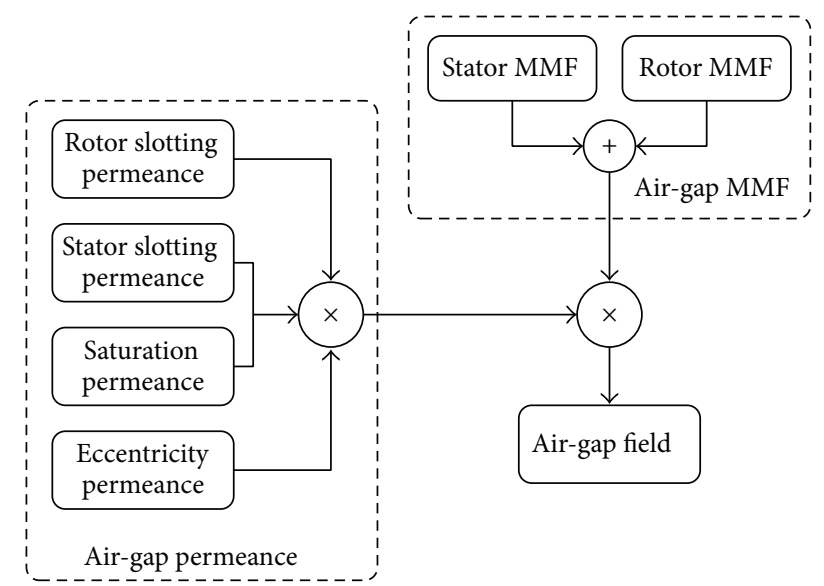

FIgURE 3: The computation style of air-gap field [35].

Therefore, the rotor slot harmonic (RSH) also called principle slot harmonics (PSH) can be derived as [37]

$$
\mathrm{PSH}=\left(k R \frac{(1-s)}{p} \pm 1\right) f
$$

where $k=1,2,3, \ldots, f$ is the line frequency in $(\mathrm{Hz})$ and $R$ is the number of rotor slots.

When static eccentricity befalls, the permeance $(P)$ is changed in the new format of

$$
P \approx P_{0}+P_{s} \cos x
$$

where $P_{s}$ is the peak of static eccentricity part in permeance $(P)$.

Accordingly, the air-gap flux components owing to the interplay of MMF (1) and permeance (7) can be written as

$$
\begin{aligned}
\Phi_{g s \_\mathrm{SE}_{1}}= & A P_{0} \cos \left(p_{n} x \pm \omega t\right)+\frac{A P_{s}}{2} \cos \left[\left(p_{n}-1\right) x \pm \omega t\right] \\
& +\frac{A P_{s}}{2} \cos \left[\left(p_{n}+1\right) x \pm \omega t\right] .
\end{aligned}
$$

Again, these flux components generate pole pair rotor MMF harmonics as $R \pm p_{n}, R \pm p_{n} \pm 1$. These harmonics comprise components including $P_{0}$ and $P_{s}$ terms where the $P_{0}$ terms incorporate with the eccentric portion and $P_{s}$ terms merge with the average part of $P$ in (7). So, the air-gap components are expressed as

$$
\begin{aligned}
\Phi_{g s_{S} \mathrm{SE}_{2}}=\frac{A_{21} P_{0} P_{s}}{2} \cos [ & \left(R \pm p_{n} \pm 1\right) x \\
& \left.-\left\{R \frac{(1-s)}{p} \pm 1\right\} \omega t-\emptyset_{21}\right] .
\end{aligned}
$$

However, the influence of harmonics comprising the $P_{s}$ terms on the eccentric part of $P$ in (7) causes increment of air-gap flux components as stated below:

$$
\begin{aligned}
\Phi_{g s_{-} \mathrm{SE}_{3}}=\frac{A_{22} P_{s}^{2}}{4} \cos [ & \left(R \pm p_{n} \pm 2\right) x \\
& \left.-\left\{R \frac{(1-s)}{p} \pm 1\right\} \omega t-\emptyset_{22}\right] .
\end{aligned}
$$

Consequently, these components are added to the air-gap flux components of (5) in the presence of static eccentricity in IMs.

In fact, the static eccentricity fault in IMs can be detected by two categories of frequencies through stator current, that is, the frequencies around fundamental harmonics which are categorized as low-frequency components and the frequencies around PSH that are classified as high-frequency components [7]. The equation describes such low-frequency components due to static eccentricity which are given in the form of $[7,38]$

$$
\begin{aligned}
& f_{\text {SE Low }}=f \pm k f_{r}, \\
& f_{r}=\left(\frac{1-s}{p}\right) \cdot f,
\end{aligned}
$$

where $f$ is fundamental frequency, $k$ is positive integer number, $f_{r}$ is the rotational frequency (speed) of motor $(\mathrm{Hz})$, $s$ is the slip, and $p$ is the pole pair number.

Meanwhile, the high-frequency components related to static eccentricity are specified in a compact form by the following equation [34]:

$$
f_{\text {SE_High }}=\left[\frac{k R(1-s)}{p} \pm v\right] \cdot f
$$

where $R$ is the number of rotor slots, $k$ is positive integer number, $s$ is slip, $p$ is the number of fundamental pole pairs, and $v$ is stator time harmonics. The \pm sign preceding $v$ is manifested due to the forward and backward rotating space harmonics which are related to sign associated with $\omega$ in (1). However, a particular relationship between $p$ and $R$ must be provided to reveal these components.

3.2. The Analytical Theory of Static Eccentricity in PMSM. The permeance of an air-gap contains stator slotting permeance and smooth rotor in PMSM which can be written as [26]

$$
P_{\mathrm{sl}}=\sum_{k_{\mathrm{sl}}=0}^{\infty} P_{k_{\mathrm{sl}}} \cos \left(k_{\mathrm{sl}} S_{1} \theta\right) \text {, }
$$

where $k_{\mathrm{sl}}$ is an integer number, $P_{k_{\mathrm{sl}}}$ is the specific permeance regarding the stator slotting, $S_{1}$ is the stator slot, and $\theta$ is the space variable. The saturation permeance is double the fundamental frequency and twice the number of poles which is mainly of the wider air-gap in the maximum flux density zone. The saturation permeance of this machine is expressed as

$$
P_{\text {sat }}=\sum_{k_{\text {sat }}=0}^{\infty} P_{k_{\text {sat }}} \cos \left[k_{\text {sat }}\left(\frac{2 \omega t}{P}-2 \theta\right)\right]
$$


where $k_{\text {sat }}$ is an integer number, $P_{k_{\text {sat }}}$ is the specific permeance of saturation, $P$ is the main pole pairs, $\omega$ is the angular supply frequency, and $t$ is time variable.

Since the nonconcentric air-gap in static eccentricity is time invariant the permeance due to this fault considering smooth rotor and stator will be

$$
P_{\mathrm{SE}}=\sum_{k_{\mathrm{SE}}=0}^{\infty} P_{k_{\mathrm{SE}}} \cos \left(k_{\mathrm{SE}} \theta\right),
$$

where $k_{\mathrm{SE}}$ is an integer number and $P_{k_{\mathrm{SE}}}$ is the specific permeance related to static eccentricity in PMSM. Moreover, the permeance based on the dynamic eccentricity is represented as

$$
P_{\mathrm{DE}}=\sum_{k_{\mathrm{DE}}=0}^{\infty} P_{k_{\mathrm{DE}}} \cos \left[k_{\mathrm{DE}}\left(\frac{\omega t}{P}-\theta\right)\right],
$$

where $k_{\mathrm{DE}}$ is an integer number and $P_{k_{\mathrm{DE}}}$ is the specific permeance concerning dynamic eccentricity in PMSM.

Accordingly, the total permeance of PMSM can be concluded with the following equation:

$$
\begin{aligned}
P_{T}(t)=\sum_{k_{\mathrm{sl}}=0}^{\infty} \sum_{k_{\mathrm{sat}}=0}^{\infty} \sum_{k_{\mathrm{SE}}=0}^{\infty} \sum_{k_{\mathrm{DE}}=0}^{\infty} P_{k_{\mathrm{sl}}, k_{\mathrm{sat}}, k_{\mathrm{SE}}, k_{\mathrm{DE}}} \\
\times \cos \left[ \pm\left(\frac{2 k_{\mathrm{sat}}+k_{\mathrm{DE}}}{P}\right) \omega t\right. \\
+\left(k_{\mathrm{sl}} S_{1} \pm 2 k_{\mathrm{sat}} P\right. \\
\left.\left. \pm k_{\mathrm{SE}} \pm k_{\mathrm{DE}}\right) \theta\right] .
\end{aligned}
$$

The air-gap flux density of PMSM can be calculated utilizing Ampere's circuital principle as

$$
B(t)=P_{T}(t) \int \mu_{0} j_{s}(\theta, t) d \theta
$$

where $\mu_{0}$ is the vacuum permeability and $j_{s}$ is the current density of stator interior surface:

$$
j_{s}(\theta, t)=\sum_{k_{j}=1}^{\infty} J_{s} \sin \left(k_{j} \omega t-P \theta\right),
$$

where $k_{j}$ is an integer number. Then, substituting (18) and (19) results in

$$
\begin{gathered}
B(t)=\frac{\mu_{0} J_{s}}{P} \sum_{k_{j}=1}^{\infty} \cos \left(k_{j} \omega t-P \theta\right) \\
\quad \times \sum_{k_{\mathrm{sl}}=0}^{\infty} \sum_{k_{\mathrm{sat}}=0}^{\infty} \sum_{k_{\mathrm{SE}}=0}^{\infty} \sum_{k_{\mathrm{DE}}=0}^{\infty} P_{k_{\mathrm{sl}}, k_{\mathrm{sat}}, k_{\mathrm{SE}}, k_{\mathrm{DE}}} \\
\times \cos \left[ \pm\left(\frac{2 k_{\mathrm{sat}}+k_{\mathrm{DE}}}{P}\right) \omega t\right. \\
+\left(k_{\mathrm{sl}} S_{1} \pm 2 k_{\mathrm{sat}} P\right. \\
\left.\left. \pm k_{\mathrm{SE}} \pm k_{\mathrm{DE}}\right) \theta\right]
\end{gathered}
$$

Equation (21) can be rewritten in the following form:

$$
\begin{aligned}
& B(t)=\frac{\mu_{0} J_{s} P_{k_{\mathrm{s}},}, k_{\mathrm{sat}}, k_{\mathrm{SE}}, k_{\mathrm{DE}}}{P} \\
& \times \sum_{k_{\mathrm{sl}}=0}^{\infty} \sum_{k_{\mathrm{sat}}=0}^{\infty} \sum_{k_{\mathrm{SE}}=0}^{\infty} \sum_{k_{\mathrm{DE}}=0}^{\infty} \cos \left[\left(k_{j} \pm\left(\frac{2 k_{\mathrm{sat}}+k_{\mathrm{DE}}}{P}\right)\right) \omega t\right. \\
&+\left( \pm k_{\mathrm{sl}} S_{1} \pm 2 k_{\mathrm{sat}} P\right. \\
&\left.\left. \pm k_{\mathrm{SE}} \pm k_{\mathrm{DE}}-P\right) \theta\right] .
\end{aligned}
$$

Eventually, (22) can be finalized as follows:

$$
\begin{array}{r}
B(t)=\sum_{\lambda, \xi} B_{\lambda, \xi} \cos \left[\left(k_{j} \pm\left(\frac{\lambda}{P}\right)\right) \omega t \pm \xi \theta\right], \quad \lambda=2 k_{\mathrm{sat}}+k_{\mathrm{DE}} \\
\xi= \pm k_{\mathrm{sl}} \theta \pm 2 k_{\mathrm{sat}} P \pm k_{\mathrm{SE}} \theta \pm k_{\mathrm{DE}} \theta-P \theta
\end{array}
$$

Heretofore, the static eccentricity analysis on the stator current of PMSMs by applying frequency domain processing technique proposed two features for diagnoses of this fault. The amplitude of the sideband components at the frequency $f_{\mathrm{SE}_{a, b, c}}$ has been introduced as an index for eccentricity detection [23]:

$$
\begin{gathered}
f_{\mathrm{SE}_{a}}=\left(\frac{2}{p_{r}}\right) \cdot f, \\
f_{\mathrm{SE}_{b}}=\left[1+\left(\frac{2}{p_{r}}\right)\right] f, \\
f_{\mathrm{SE}_{c}}=\left[2+\left(\frac{2}{p_{r}}\right)\right] f,
\end{gathered}
$$

where $p_{r}$ is the number of poles and $f$ is the fundamental frequency. The stator current of a healthy PMSM is principally comprised of fundamental frequency, which is the rotor frequency multiplied by number of pole pairs. Whenever the static eccentricity takes place, the new harmonic component will manifest itself in the current signal. One stator electrical fundamental period produces $\left(2 / p_{r}\right)$ rotation for a $p_{r}$-pole PMSM. Despite the fact that the position of narrowest airgap is static, the new harmonic components will appear at the rotating frequency where they can be diagnosed based on $f_{\mathrm{SE}_{a}}, f_{\mathrm{SE}_{b}}$, and $f_{\mathrm{SE}_{c}}$ considering the fact that these new components and multiples thereof are not encountered in the winding inductances and flux linkage though there is diversity in inductances among the phases.

The amplitude of sideband components at the following frequencies is recommended as a suitable feature for static eccentricity detection in PMSM [24]:

$$
f_{\mathrm{SE}}=\left[1 \pm\left(\frac{2 k-1}{p}\right)\right] f
$$


where $k$ is an integer number, $p$ is pole pairs number, and $f$ is supply frequency. The MMF of the stator is expressed as

$$
F_{s}=\frac{B(t)}{P_{T}(t)} .
$$

The stator current involving space and time harmonics is as follows:

$$
i(t)=\sum_{\lambda, \xi} I_{\lambda, \xi} \cos \left[\left(k_{j} \pm\left(\frac{\lambda}{p}\right)\right) \omega t \pm \xi \theta\right] .
$$

Equation (27) is simplified for sinusoidal supply voltage as

$$
i(t)=\sum_{\lambda, \xi} I_{\lambda, \xi} \cos \left[\left(1 \pm\left(\frac{\lambda}{p}\right)\right) \omega t \pm \xi \theta\right],
$$

where $\lambda=1,3,5, \ldots$. So, the time series of the stator current can be written as follows:

$$
i(t)=\sum_{k=0}^{\infty} I_{k} \cos \left[\left(1 \pm \frac{2 k-1}{p}\right) \omega t \pm \Phi_{k}\right],
$$

where $k$ is an integer number and $\Phi_{k}$ is the space variable. Therefore, the $f_{\mathrm{SE}}$ can be extracted from (29).

3.3. Static Eccentricity Prediction in LSPMSM. Hitherto no work has been carried out to investigate the effect of eccentricity fault in LSPMSM, although the application of this high efficiency motor is increasing. The LSPMSM utilizes the induction characteristic during the startup as transient operation while following the synchronization phenomenon during the steady state condition at synchronous speed. Hereupon, the investigation into LSPMSM under static eccentricity at steady state operation is worthwhile in order to pinpoint a signature for this fault as the subsequent upkeep. Indeed, the stator current analysis is a prominent technique for static eccentricity diagnosis in various types of motor which is also expected to provide valuable results for LSPMSM.

It can be suggested that the static eccentricity scrutiny in LSPMSM can be effectively pursued utilizing the aforementioned indexes for IM and PMSM as the possible frequency components in this case. Therefore, (11) can be rewritten as

$$
f_{\mathrm{SE}_{1}}=\left(1 \pm \frac{k}{p}\right) f
$$

where $k=1,2,3, \ldots, p$ is the number of pole pairs and $f$ is supply frequency. Besides, (13) will be in the form of

$$
f_{\mathrm{SE}_{2}}=\left(k \frac{R}{p} \pm v\right) f
$$

where $R$ is the number of rotor slots, $v=1,3,5, \ldots$ Moreover, the sequence of (24) also can be introduced as

$$
f_{\mathrm{SE}_{3}}=\left[k_{3}+\left(\frac{2}{p_{r}}\right)\right] f,
$$

where $k_{3}=0,1,2$ and $p_{r}$ is the number of poles. Equation (25) is another index that can be examined for static eccentricity detection in LSPMSM.
TABLE 1: Specification of the three-phase LSPMSM.

\begin{tabular}{lc}
\hline Rated output power (HP) & 1 \\
Rated voltage (V) & 415 \\
Rated frequency (Hz) & 50 \\
Number of poles & 4 \\
Rated speed (RPM) & 1500 \\
Air-gap length (mm) & 0.30 \\
Number of stator slots & 24 \\
Number of rotor slots & 16 \\
Effective length of stator core (mm) & 72 \\
Stator outer diameter (mm) & 120 \\
Height of stator yoke (mm) & 45 \\
Height of stator slot (mm) & 13 \\
Height of rotor slot (mm) & 8 \\
Number of turns per slot & 139 \\
Magnet material & $\mathrm{N} 38 \mathrm{SH}$ \\
Remanent flux density of magnets (T) & 1.235 \\
\hline
\end{tabular}

\section{Modeling of LSPMSM Using Finite Element Method}

A meticulous modeling on the basis of genuine structure is the significant stage that steers towards authentic fault detection in LSPMSM. Finite element method (FEM) is a numerical approach which can be employed for computing the parameters of electrical motors such as flux density, inductance, current, induced EMF, and torque. This method divides the model of motor into small segments by a particular mesh operation. Each segment is represented via a set of equations and the combination of all segments produces an enormous set of equations that demonstrate the motor. FEM is a precise analysis as the inductances can be directly calculated by field analysis, so various conditions such as slot effects and saturation are spontaneously taken into account [39].

A three-phase LSPMSM is modeled in 2D environment on the basis of FEM using Maxwell 2D software. The specification of the LSPMSM has been summarized in Table 1. Three-phase sinusoidal voltages are applied to the motor terminals as windings excitation. The transient solver with time integration method based on backward Euler is employed to solve the steady state current of LSPMSM. The model comprises all geometrical and physical complexities of machine parts such as stator, rotor, and shaft, in addition to stator winding distribution, nonuniform permeance of airgap because of eccentricity, nonlinear characteristics of stator and rotor cores, and permanent magnets materials. The $2 \mathrm{D}$ scheme of simulated LSPMSM with nonuniform air-gap due to static eccentricity is shown in Figure 4.

The materials characteristic and stator winding formation highly influence the fault detection criteria [16, 40]. The stator and rotor cores are composed of laminated silicon steel; permanent magnet model of $\mathrm{N} 38 \mathrm{H}$ with relative permeability of $\mu_{r}=1.326$ is utilized in the rotor structure; rotor bars 


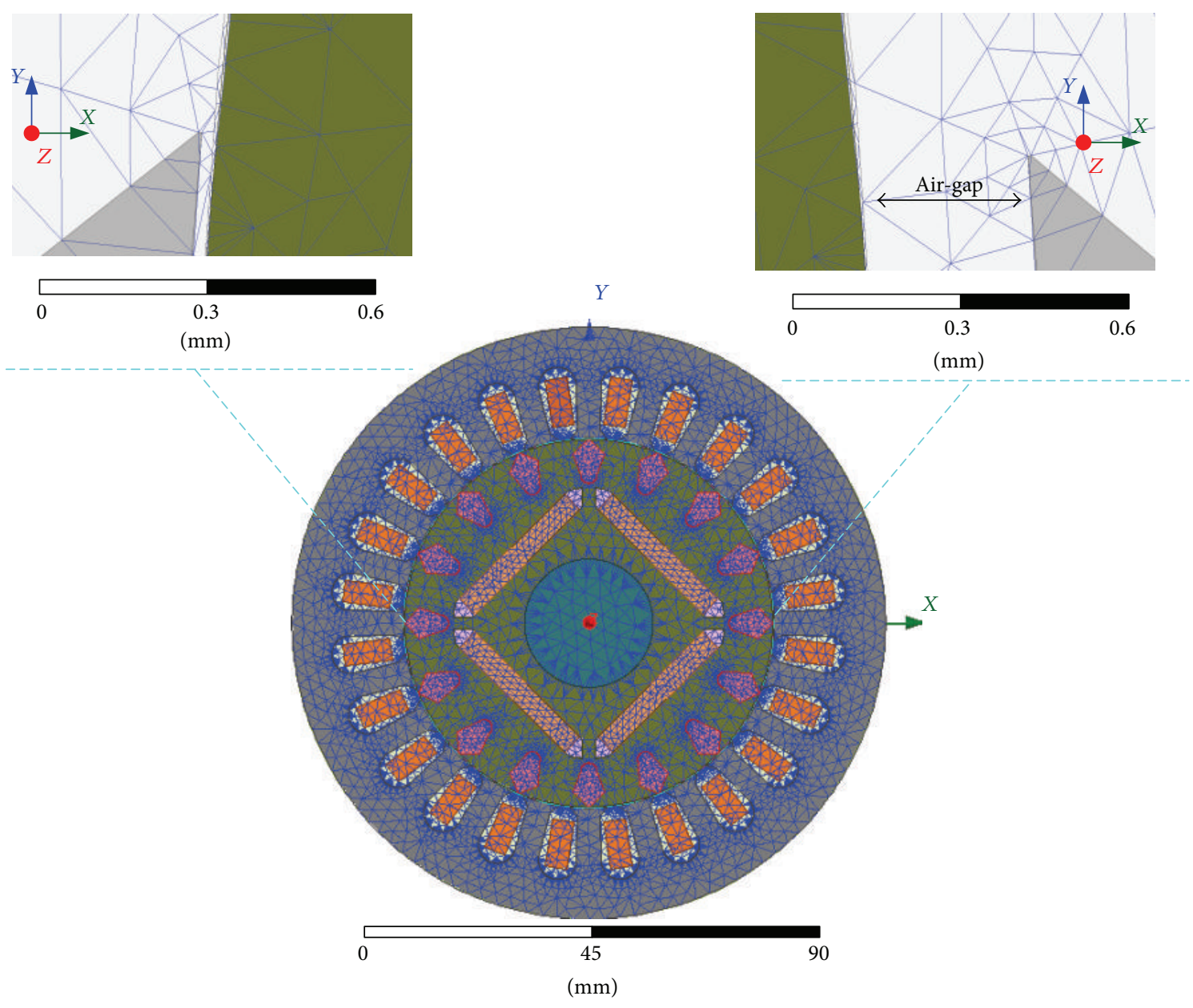

FIGURE 4: Geometric configurations of simulated faulty LSPMSM using 2D FEM.

are constructed by cast aluminum; and copper is used as conductor in the stator winding configuration. Monolayer distributed windings is arranged in the stator slots in order to minimize the harmonics of line current and voltage in this motor, results in higher efficiency and higher quality signal for fault detection.

The magnetic parameters and motor geometric extents are utilized by FEM to compute the magnetic field distribution inside the motor. Afterwards, the magnetic field distribution is employed to calculate other parameters such as induced voltage, inductances, current, torque, and speed. As the eccentric motor is modeled with an asymmetric air-gap, the calculated current, torque, and speed are also asymmetrical. This asymmetry condition generates several harmonic components in magnetic field, current, and torque of the motor. The new harmonics in the stator current can be determined as a frequency pattern for static eccentricity detection in LSPMSM.

The objective of this paper follows by modeling of static eccentricity fault in different degrees, so the aforementioned procedure shown in Figure 2 has been pursued; that is, the center of rotor is moved from the center of stator while rotating concentrically with its own center. Figure 5 depicts the location of stator and rotor under static eccentricity condition where $C_{s}$ is the center of stator, $C_{r}$ is the center of rotor, $C_{g}$ is the center of rotation, $\beta_{s}$ is the primary angle of static eccentricity, and vector $\overrightarrow{C_{s} C_{g}}$ is the static transfer vector which is invariant for rotor angular positions.

Therefore, the degree of static eccentricity can be calculated by the following equation [24]:

$$
D_{\mathrm{SE}}=\frac{\left|C_{s} C_{g}\right|}{g},
$$

where $g$ is the uniform air-gap length. The performance of 4-pole LSPMSM in healthy and faulty conditions including time variations of current, speed, and torque is presented in Figure 6. The differences between these figures clarify the effect of static eccentricity in LSPMSM as such synchronization process of motor takes longer time under faulty condition to reach steady state. 


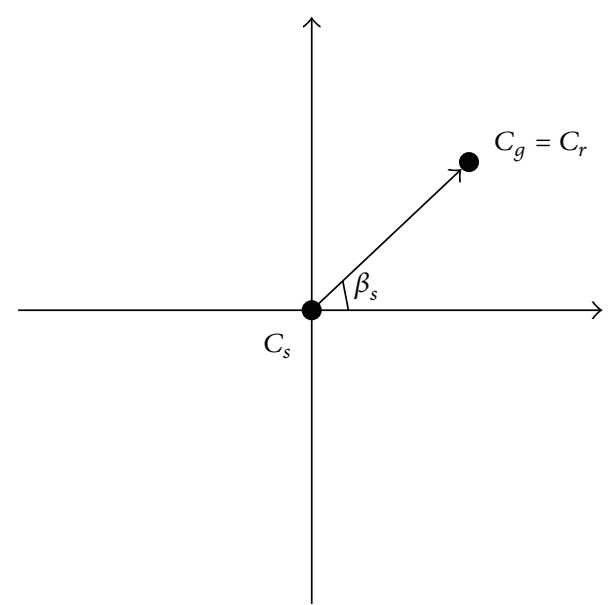

FIGURE 5: The location of stator and rotor under static eccentricity condition [24].

\section{Investigation of Proposed Frequency Patterns for LSPMSM}

It is worthwhile to investigate the ability of aforementioned features for static eccentricity fault diagnosis using stator current in LSPMSM. Accordingly, the stationary signal of stator current is stored and analyzed in frequency domain applying power spectral density (PSD) analysis. The PSD spectrum has been normalized with respect to the fundamental component. The simulated signals are captured with the sampling frequency of $5 \mathrm{kHz}$ over a total sampling time of $6.5 \mathrm{~s}$ which provides $0.15 \mathrm{~Hz}$ frequency resolution in the spectrum analysis. Due to intrinsic eccentricity level of $10 \%$ which exists in practical condition [32], the eccentric motor in this study is modeled with $16.6 \%$ fault degree to evaluate the ability of fault-related feature for detecting static eccentricity at early stages. Then, the higher degrees of static eccentricity such as $66 \%$ and $83 \%$ are considered to observe the effect of fault severity in this motor. The different orders of harmonic components due to static eccentricity which should be scanned in the stator current spectrum are summarized in Table 2. Meanwhile, the PSD measurements of the line current for healthy and faulty LSPMSM with $16.6 \%, 66 \%$, and $83 \%$ static eccentricity are shown in Figures 7 and 8.

It can be concluded from Figure 7 that static eccentricity generates harmonic components in stator current where their amplitudes are changed due to the fault severity. Comparison between healthy (Figure $7(\mathrm{a})$ ) and faulty conditions (Figure 7(b)) reveals the increase in the amplitude of sideband components at frequency $(1 \pm k / 2) f$ on account of fault progress. Meanwhile, the differences between Figures 7 (a) and $7(d)$ manifest a considerable rise of the amplitudes at frequencies $(1 \pm k / 2) f$ for $k=1$ and 3 , that is, $25 \mathrm{~Hz}, 75 \mathrm{~Hz}$, and $125 \mathrm{~Hz}$.

Despite the sideband component at frequency of $(1 \pm$ 2/2) $f$, that is, $100 \mathrm{~Hz}$ can be calculated in this case, but a survey in [24] inferred that the main field begets harmonics because of associated rotating force wave at frequencies $50 \mathrm{~Hz}, 100 \mathrm{~Hz}, 150 \mathrm{~Hz}, 200 \mathrm{~Hz}, \ldots$, and so forth, so long as $k$
TABLE 2: Current frequency components and their order due to static eccentricity in 4-pole LSPMSM.

\begin{tabular}{lc}
\hline Harmonic frequency $f_{\mathrm{SE}}$ & Order \\
\hline$\left(1 \pm \frac{k}{p}\right) f$ & $1+\frac{k}{2}$ \\
\hline$\left(k \frac{R}{p} \pm v\right) f$ & $1-\frac{k}{2}$ \\
\hline$\left[k_{3}+\left(\frac{2}{p_{r}}\right)\right] f$ & $8 k+1$ \\
& $8 k-1$ \\
\hline$\left[1 \pm\left(\frac{2 k-1}{p}\right)\right] f$ & $1+\frac{2}{4}$ \\
\hline
\end{tabular}

is an even integer value; while the amplitude of main field harmonics is superior to the eccentricity components, then the eccentricity components at frequencies $50 \mathrm{~Hz}, 100 \mathrm{~Hz}, \ldots$, are negligible. Consequently, the frequency pattern $(1 \pm k / 2) f$ can be effective for LSPMSM when $k$ is an odd integer value. It is noticeable that the static eccentricity components at frequency $100 \mathrm{~Hz}$ are visible in the 4-pole LSPMSM.

On the other side, the frequency pattern $[1 \pm(2 k-$ 1)/2] $f$ pinpoints the same frequency components due to static eccentricity for $k=1$ and 2 , that is, $25 \mathrm{~Hz}, 75 \mathrm{~Hz}$, and $125 \mathrm{~Hz}$. Indeed, this frequency pattern follows the same aforementioned configuration of $(1 \pm k / 2) f$ when $k$ is an odd integer value. Therefore, similar harmonic components will be nominated using these two indexes for static eccentricity detection in LSPMSM. By the way, harmonic components $(2 / 4) f, 25 \mathrm{~Hz},[1+(2 / 4)] f, 75 \mathrm{~Hz}$, and $[2+(2 / 4)] f, 125 \mathrm{~Hz}$, determine identical frequencies for static eccentricity signature in LSPMSM. As a result, these three features expose uniform behaviors in order to pinpoint the static eccentricity frequency components in the proposed LSPMSM.

A comparison of Figures 8(a), 8(b), 8(c), and 8(d) draws attention to the posture of harmonic frequencies $(8 k \pm 1) f$ in 4-pole LSPMSM with 16 rotor slots. The frequencies $350 \mathrm{~Hz}$ and $450 \mathrm{~Hz}$ are computed for $k=1$. It can be seen that amplitudes of components at $350 \mathrm{~Hz}$ do not indicate remarkable changes due to static eccentricity in this motor. Though the intensive levels of static eccentricity increase the amplitude of harmonic component in frequency $450 \mathrm{~Hz}$ which is obvious in Figure 8(d), these high-frequency components in the current signal are found to be weak for this motor. The evaluation of aforementioned features due to $16.6 \%, 66 \%$, and $83 \%$ static eccentricity is summarized in Table 3.

It can be derived from the results that the following index is an appropriate signature to pinpoint the static eccentricity in LSPMSM:

$$
f_{\text {static }}=\left[1 \pm \frac{m}{p}\right] f
$$




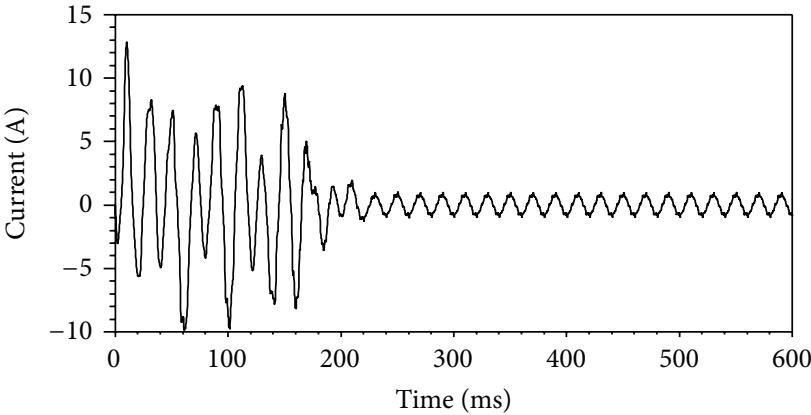

(a)

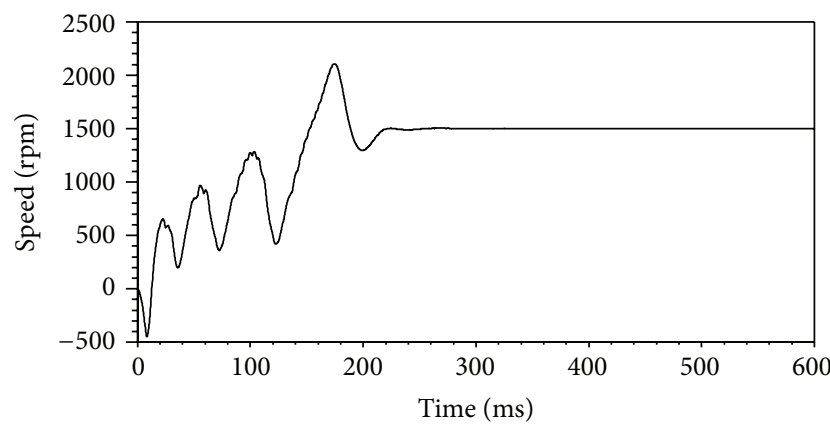

(c)

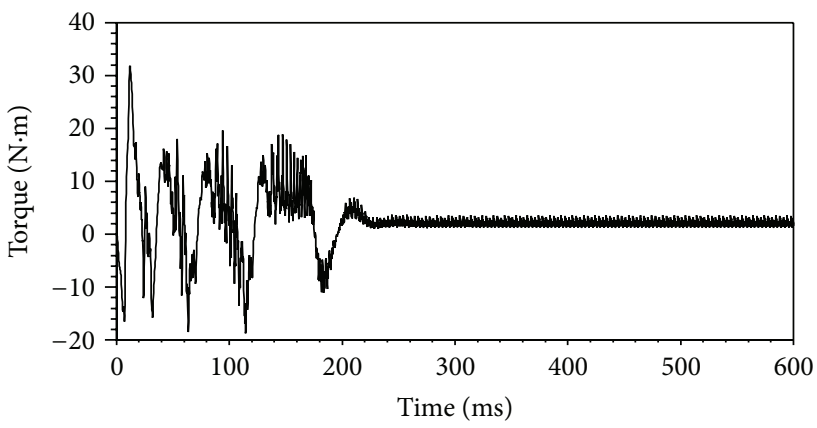

(e)

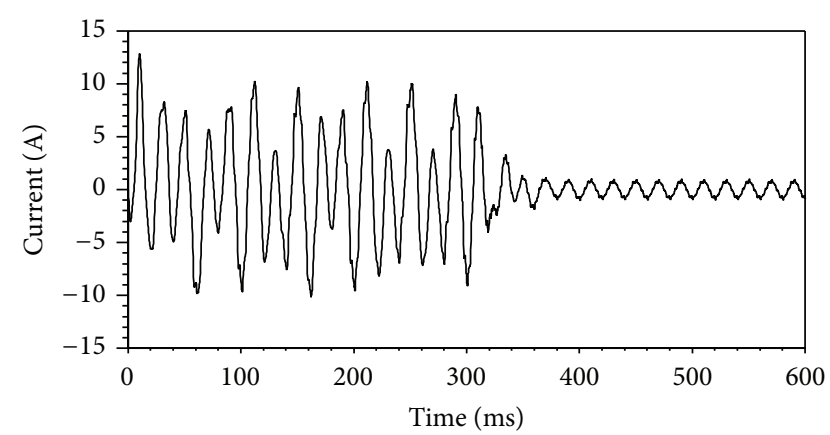

(b)

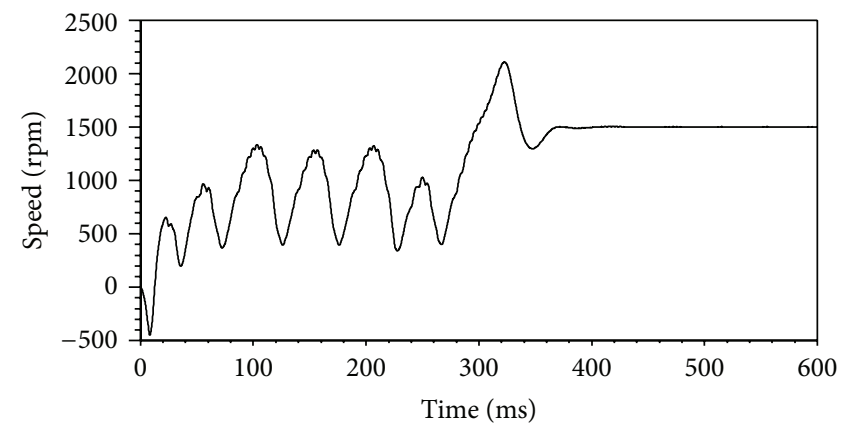

(d)

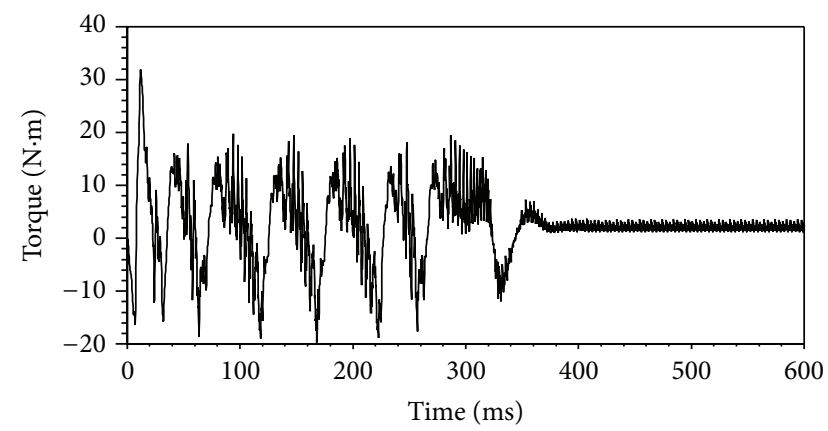

(f)

FIGURE 6: Time variation profiles of LSPMSM. Left: healthy condition; right: motor with static eccentricity; ((a), (b)) phase current; ((c), (d)) speed; and ((e), (f)) torque.

where $f_{\text {static }}$ is the harmonic components due to static eccentricity in LSPMSM, $m$ is an odd integer value, $p$ is the number of pole pairs, and $f$ is the line frequency. It can be found in Figure 7(b) that the proposed index is efficient for static eccentricity detection in $16.6 \%$ eccentricity degree; therefore, it is reliable for early stage fault detection in LSPMSM.

\section{Conclusion}

In this paper, performance of LSPMSM under static eccentricity fault during steady state operation was analyzed employing FEM. The effects of static eccentricity on the harmonic content of stator line current have been scrutinized in frequency domain to propose a criterion for static eccentricity detection in this hybrid type of electrical motors. In this regard, previous features suggested for static eccentricity diagnosis using stator current signal in IMs and PMSMs are studied carefully to evaluate their possibilities in LSPMSM. It is observed that $\left[k_{3}+\left(2 / p_{r}\right)\right] f,[1 \pm(2 k-1 / p)] f$, and $f \pm k f_{r}$ (for odd values of $k$ while slip is always zero in synchronous motors) are converged to the same harmonic frequencies. Indeed, the frequency pattern $[1 \pm(2 k-1 / p)] f$ is similar to $f \pm k f_{r}$ when $k$ is an odd value, at synchronous condition. It is concluded that the low-frequency sideband components are the perfect signatures for static eccentricity and its degree in LSPMSM which can be predicted by frequency pattern $[1 \pm$ $(m / p)] f$. The higher degrees of fault increase the amplitude of these components which can be utilized to estimate the degree of static eccentricity. This frequency pattern is reliable for static eccentricity detection at early stage. It is noticeable that the harmonic components related to static eccentricity can be changed in LSPMSM with different number of pole pairs. 


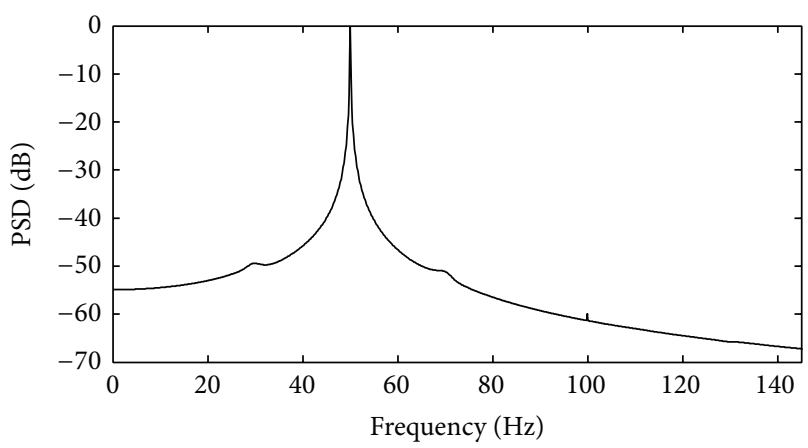

(a)

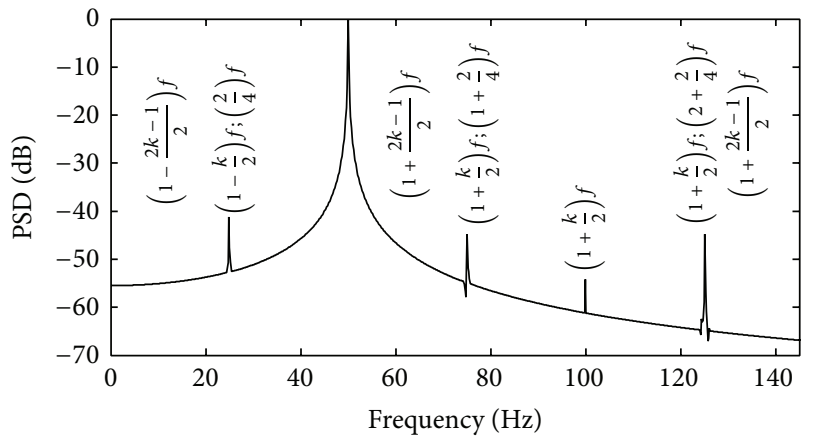

(c)

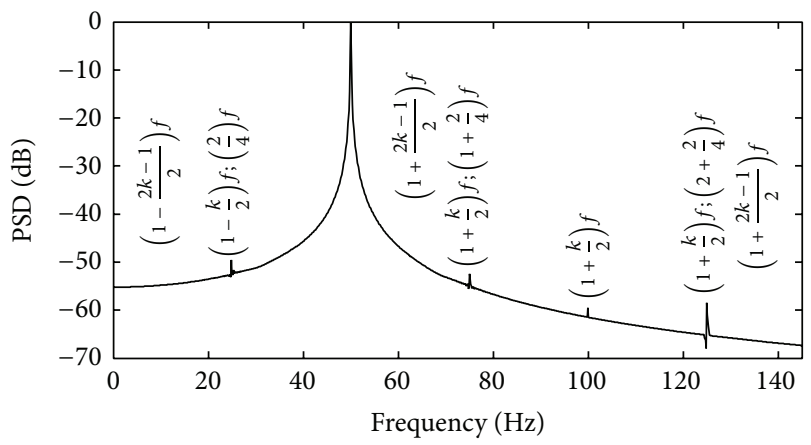

(b)

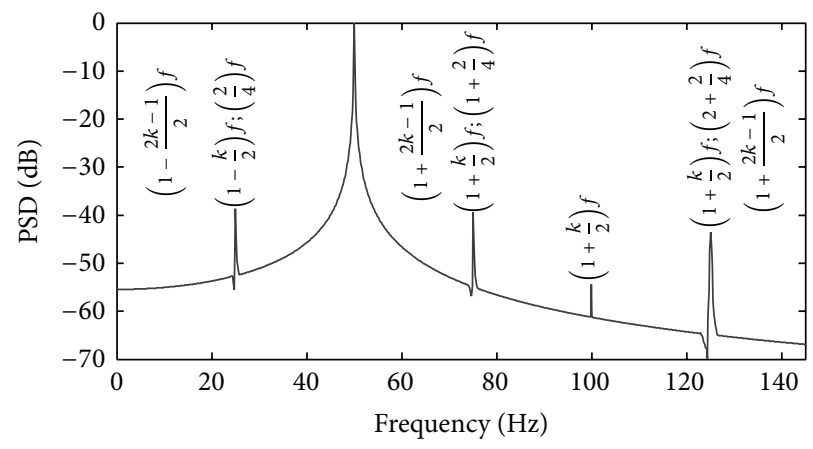

(d)

FIGURE 7: Normalized PSD spectrum of stator current of LSPMSM. (a) Healthy condition; (b) with 16.6\% static eccentricity; (c) with 66\% static eccentricity; and (d) with $83 \%$ static eccentricity.

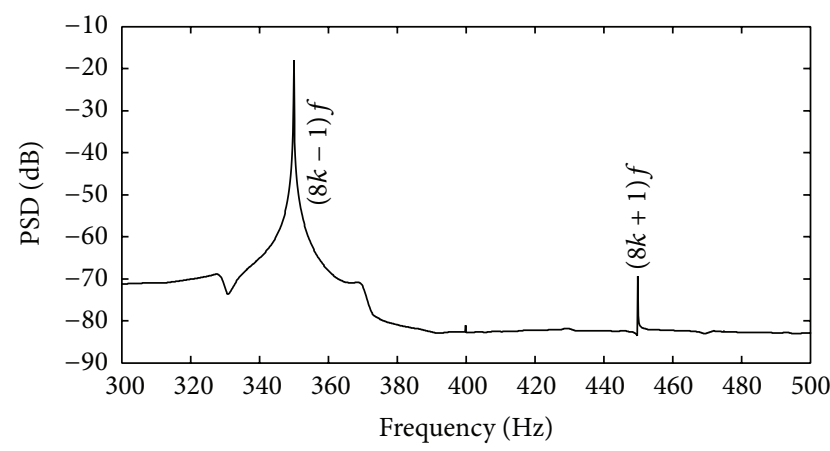

(a)

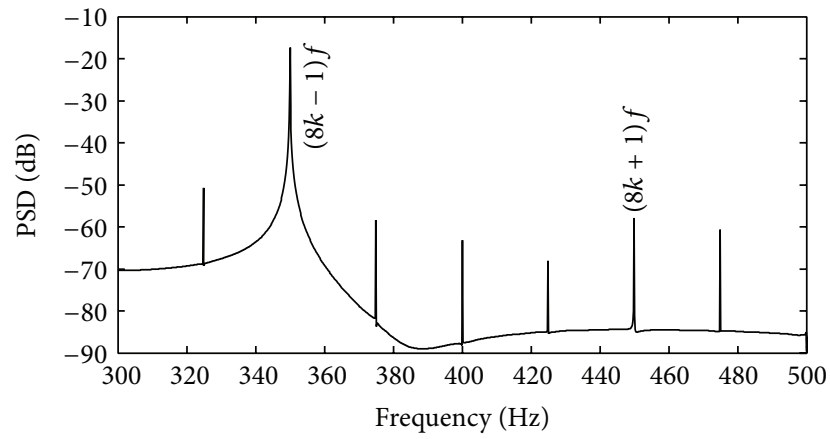

(c)

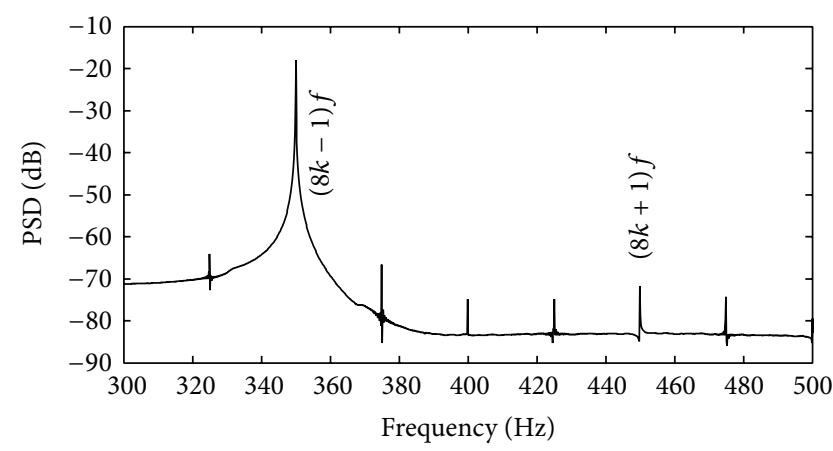

(b)

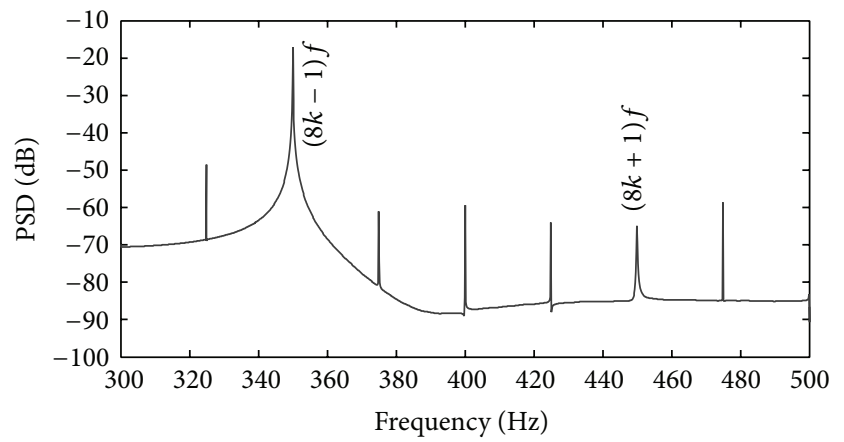

(d)

Figure 8: Normalized stator current spectrum of LSPMSM. (a) Healthy condition; (b) with $16.6 \%$ static eccentricity; (c) with $66 \%$ static eccentricity; and (d) with $83 \%$ static eccentricity. 
TABLE 3: Frequencies and amplitudes of harmonic components due to static eccentricity in LSPMSM.

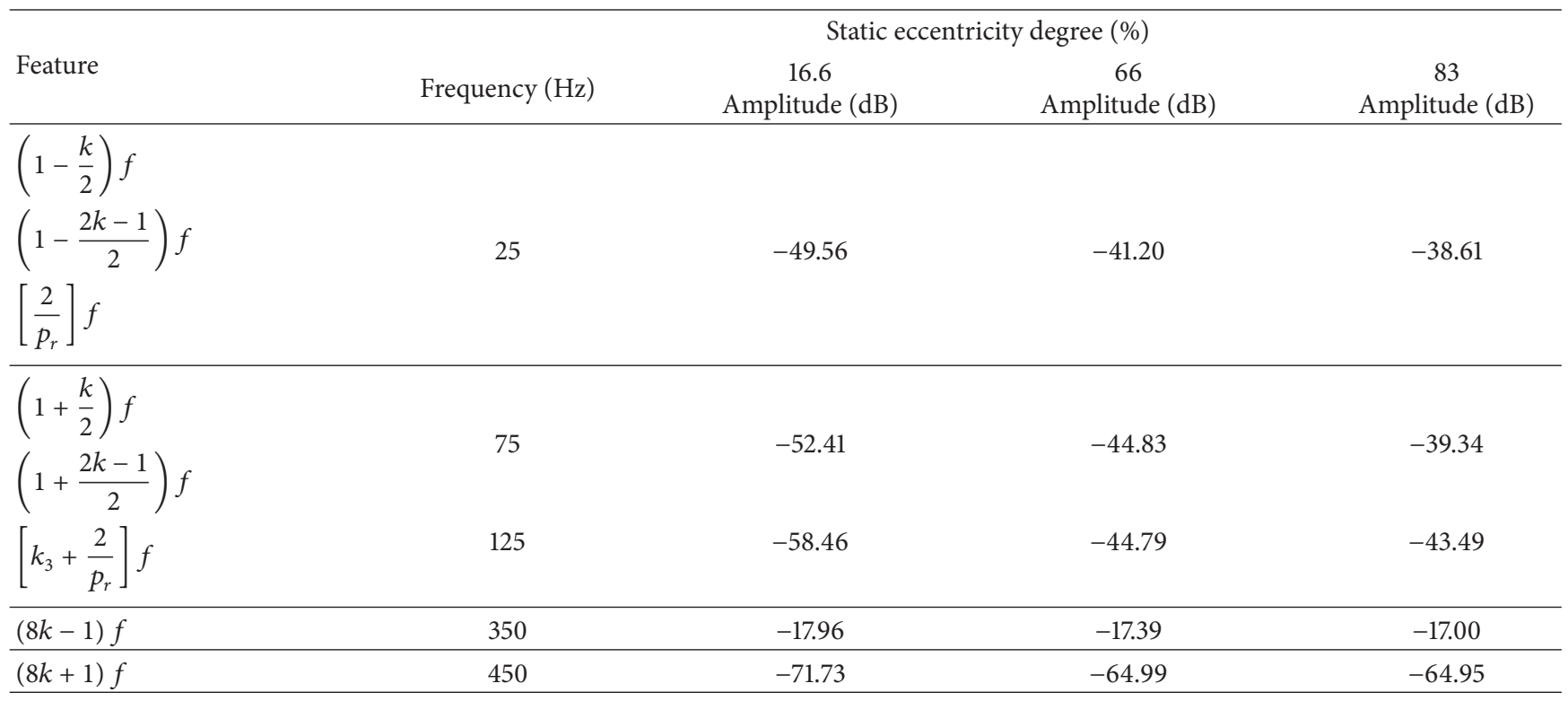

\section{Conflict of Interests}

The authors declare that there is no conflict of interests regarding the publication of this paper.

\section{Acknowledgments}

The authors would like to express their gratitude to the Ministry of Education of Malaysia for financial support through Grant no. FRGS-5524356 and Universiti Putra Malaysia for the facilities provided during this research work.

\section{References}

[1] S. Toosi, M. R. Mehrjou, M. Karami, and M. R. Zare, "Increase performance of IPMSM by combination of maximum torque per ampere and flux-weakening methods," ISRN Power Engineering, vol. 2013, Article ID 187686, 10 pages, 2013.

[2] A. M. Knight and C. I. McClay, "The design of high-efficiency line-start motors," IEEE Transactions on Industry Applications, vol. 36, no. 6, pp. 1555-1562, 2000.

[3] A. H. Isfahani and S. Vaez-Zadeh, "Line start permanent magnet synchronous motors: challenges and opportunities," Energy, vol. 34, no. 11, pp. 1755-1763, 2009.

[4] G.-H. Kang, J. Hur, H. Nam, J.-P. Hong, and G.-T. Kim, "Analysis of irreversible magnet demagnetization in line-start motors based on the finite-element method," IEEE Transactions on Magnetics, vol. 39, no. 3 I, pp. 1488-1491, 2003.

[5] W. H. Kim, K. C. Kim, S. J. Kim et al., "A study on the optimal rotor design of lspm considering the starting torque and efficiency," IEEE Transactions on Magnetics, vol. 45, no. 3, pp. 1808-1811, 2009.

[6] W. Fei, P. C. K. Luk, J. Ma, J. X. Shen, and G. Yang, "A highperformance line-start permanent magnet synchronous motor amended from a small industrial three-phase induction motor," IEEE Transactions on Magnetics, vol. 45, no. 10, pp. 4724-4727, 2009.
[7] J. Faiz, B. M. Ebrahimi, B. Akin, and H. A. Toliyat, "Comprehensive eccentricity fault diagnosis in induction motors using finite element method," IEEE Transactions on Magnetics, vol. 45, no. 3, pp. 1764-1767, 2009.

[8] J. Faiz, B. M. Ebrahimi, and M. B. B. Sharifian, "Different faults and their diagnosis techniques in three-phase squirrel-cage induction motors-a review," Electromagnetics, vol. 26, no. 7, pp. 543-569, 2006.

[9] K. Yahia, A. J. M. Cardoso, A. Ghoggal, and S. E. Zouzou, "Induction motors airgap-eccentricity detection through the discrete wavelet transform of the apparent power signal under non-stationary operating conditions," ISA Transactions, vol. 53, no. 2, pp. 603-611, 2014.

[10] J. Faiz, I. Tabatabaei, and E. Sharifi-Ghazvini, "A precise electromagnetic modeling and performance analysis of a threephase squirrel-cage induction motor under mixed eccentricity condition," Electromagnetics, vol. 24, no. 6, pp. 471-489, 2004.

[11] B. M. Ebrahimi, M. Etemadrezaei, and J. Faiz, "Dynamic eccentricity fault diagnosis in round rotor synchronous motors," Energy Conversion and Management, vol. 52, no. 5, pp. 20922097, 2011.

[12] B. L. Rajalakshmi Samaga and K. P. Vittal, "Comprehensive study of mixed eccentricity fault diagnosis in induction motors using signature analysis," International Journal of Electrical Power and Energy Systems, vol. 35, no. 1, pp. 180-185, 2012.

[13] M. Sahraoui, A. Ghoggal, S. E. Zouzou, and M. E. Benbouzid, "Dynamic eccentricity in squirrel cage induction motorssimulation and analytical study of its spectral signatures on stator currents," Simulation Modelling Practice and Theory, vol. 16, no. 9, pp. 1503-1513, 2008.

[14] W. T. Thomson and A. Barbour, "On-line current monitoring and application of a finite element method to predict the level of static airgap eccentricity in three-phase induction motors," IEEE Transactions on Energy Conversion, vol. 13, no. 4, pp. 347354, 1998.

[15] J. Faiz and S. Pakdelian, "Diagnosis of static eccentricity in switched reluctance motors based on mutually induced voltages," IEEE Transactions on Magnetics, vol. 44, no. 8, pp. 20292034, 2008. 
[16] B. M. Ebrahimi, M. Javan Roshtkhari, J. Faiz, and S. V. Khatami, "Advanced eccentricity fault recognition in permanent magnet synchronous motors using stator current signature analysis," IEEE Transactions on Industrial Electronics, vol. 61, no. 4, pp. 2041-2052, 2014.

[17] M. R. Mehrjou, N. Mariun, M. Karami, N. Misron, S. Toosi, and M. R. Zare, "Evaluation of wavelet-functions for broken rotor bar detection of induction machine using coefficientrelated features," The International Journal of Applied Electronics in Physics \& Robotics, vol. 1, no. 1, pp. 18-23, 2013.

[18] S. Nandi, H. A. Toliyat, and X. Li, "Condition monitoring and fault diagnosis of electrical motors-a review," IEEE Transactions on Energy Conversion, vol. 20, no. 4, pp. 719-729, 2005.

[19] G. K. Singh and S. A. S. Al Kazzaz, "Induction machine drive condition monitoring and diagnostic research-a survey," Electric Power Systems Research, vol. 64, no. 2, pp. 145-158, 2003.

[20] J. R. Cameron, W. T. Thomson, and A. B. Dow, "Vibration and current monitoring for detecting airgap eccentricity in large induction motors," IEE Proceedings B: Electric Power Applications, vol. 133, no. 3, pp. 155-163, 1986.

[21] J. Faiz and M. Ojaghi, "Different indexes for eccentricity faults diagnosis in three-phase squirrel-cage induction motors: a review," Mechatronics, vol. 19, no. 1, pp. 2-13, 2009.

[22] S. Nandi, S. Ahmed, and H. A. Toliyat, "Detection of rotor slot and other eccentricity related harmonics in a three phase induction motor with different rotor cages," IEEE Transactions on Energy Conversion, vol. 16, no. 3, pp. 253-260, 2001.

[23] W. le Roux, R. G. Harley, and T. G. Habetler, "Detecting rotor faults in low power permanent magnet synchronous machines," IEEE Transactions on Power Electronics, vol. 22, no. 1, pp. 322328, 2007.

[24] B. M. Ebrahimi, J. Faiz, and M. J. Roshtkhari, "Static-, dynamic, and mixed-eccentricity fault diagnoses in permanent-magnet synchronous motors," IEEE Transactions on Industrial Electronics, vol. 56, no. 11, pp. 4727-4739, 2009.

[25] T.-J. Kim, S.-M. Hwang, K.-T. Kim, W.-B. Jung, and C.-U. Kim, "Comparison of dynamic responses for IPM and SPM motors by considering mechanical and magnetic coupling," IEEE Transactions on Magnetics, vol. 37, no. 4, pp. 2818-2820, 2001.

[26] B. M. Ebrahimi, J. Faiz, and B. N. Araabi, "Pattern identification for eccentricity fault diagnosis in permanent magnet synchronous motors using stator current monitoring," IET Electric Power Applications, vol. 4, no. 6, pp. 418-430, 2010.

[27] A. H. Bonnett and G. C. Soukup, "Cause and analysis of stator and rotor failures in three-phase squirrel-cage induction motors," IEEE Transactions on Industry Applications, vol. 28, no. 4, pp. 921-937, 1992.

[28] M. Akar, "Detection of a static eccentricity fault in a closed loop driven induction motor by using the angular domain order tracking analysis method," Mechanical Systems and Signal Processing, vol. 34, no. 1-2, pp. 173-182, 2013.

[29] M. Seera, C. P. Lim, S. Nahavandi, and C. K. Loo, "Condition monitoring of induction motors: a review and an application of an ensemble of hybrid intelligent models," Expert Systems with Applications, vol. 41, no. 10, pp. 4891-4903, 2014.

[30] H. Torkaman and E. Afjei, "Sensorless method for eccentricity fault monitoring and diagnosis in switched reluctance machines based on stator voltage signature," IEEE Transactions on Magnetics, vol. 49, no. 2, pp. 912-920, 2013.
[31] J. Hong, S. Park, D. Hyun et al., "Detection and classification of rotor demagnetization and eccentricity faults for PM synchronous motors," IEEE Transactions on Industry Applications, vol. 48, no. 3, pp. 923-932, 2012.

[32] D. Hyun, J. Hong, S. B. Lee et al., "Automated monitoring of airgap eccentricity for inverter-fed induction motors under standstill conditions," IEEE Transactions on Industry Applications, vol. 47, no. 3, pp. 1257-1266, 2011.

[33] D. G. Dorrell and C. Cossar, "A vibration-based condition monitoring system for switched reluctance machine rotor eccentricity detection," IEEE Transactions on Magnetics, vol. 44, no. 9, pp. 2204-2214, 2008.

[34] S. Nandi, T. C. Ilamparithi, S. B. Lee, and D. Hyun, "Detection of eccentricity faults in induction machines based on nameplate parameters," IEEE Transactions on Industrial Electronics, vol. 58, no. 5, pp. 1673-1683, 2011.

[35] H. Guldemir, "Detection of airgap eccentricity using line current spectrum of induction motors," Electric Power Systems Research, vol. 64, no. 2, pp. 109-117, 2003.

[36] M. M. Liwschitz, "Field harmonics in induction motors," Transactions of the American Institute of Electrical Engineers, vol. 61, no. 11, pp. 797-803, 1942.

[37] R. Sharifi and M. Ebrahimi, "Detection of stator winding faults in induction motors using three-phase current monitoring," ISA Transactions, vol. 50, no. 1, pp. 14-20, 2011.

[38] W. T. Thomson, D. Rankin, and D. G. Dorrell, "On-line current monitoring to diagnose airgap eccentricity in large threephase induction motors-industrial case histories verify the predictions," IEEE Transactions on Energy Conversion, vol. 14, no. 4, pp. 1372-1378, 1999.

[39] S. A. Taher and M. Malekpour, "A novel technique for rotor bar failure detection in single-cage induction motor using FEM and MATLAB/SIMULINK," Mathematical Problems in Engineering, vol. 2011, Article ID 620689, 14 pages, 2011.

[40] D. Casadei, F. Filippetti, C. Rossi, and A. Stefani, "Magnets faults characterization for permanent magnet synchronous motors," in Proceedings of the IEEE International Symposium on Diagnostics for Electric Machines, Power Electronics and Drives (SDEMPED '09), pp. 1-6, IEEE, Cargèse, France, September 2009. 


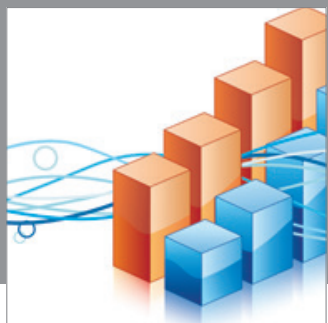

Advances in

Operations Research

mansans

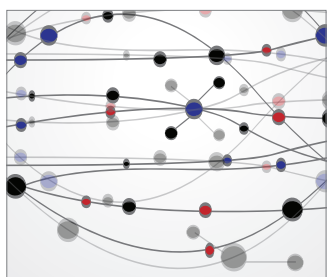

The Scientific World Journal
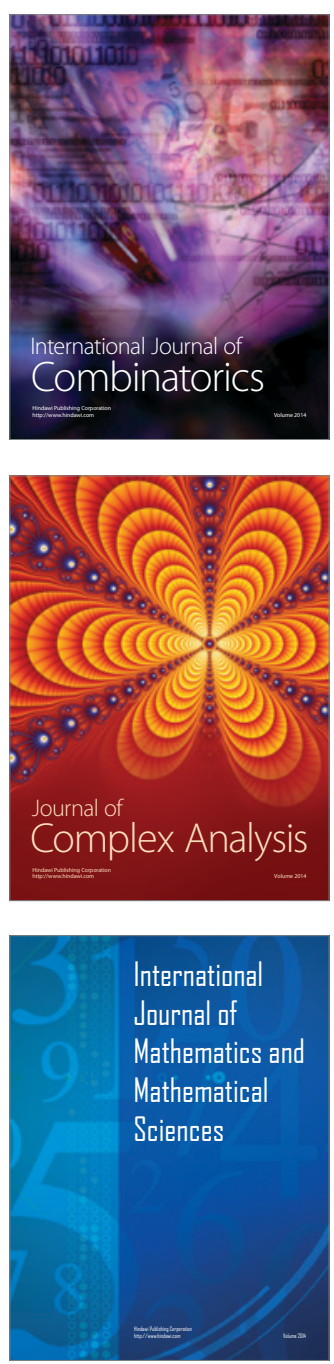
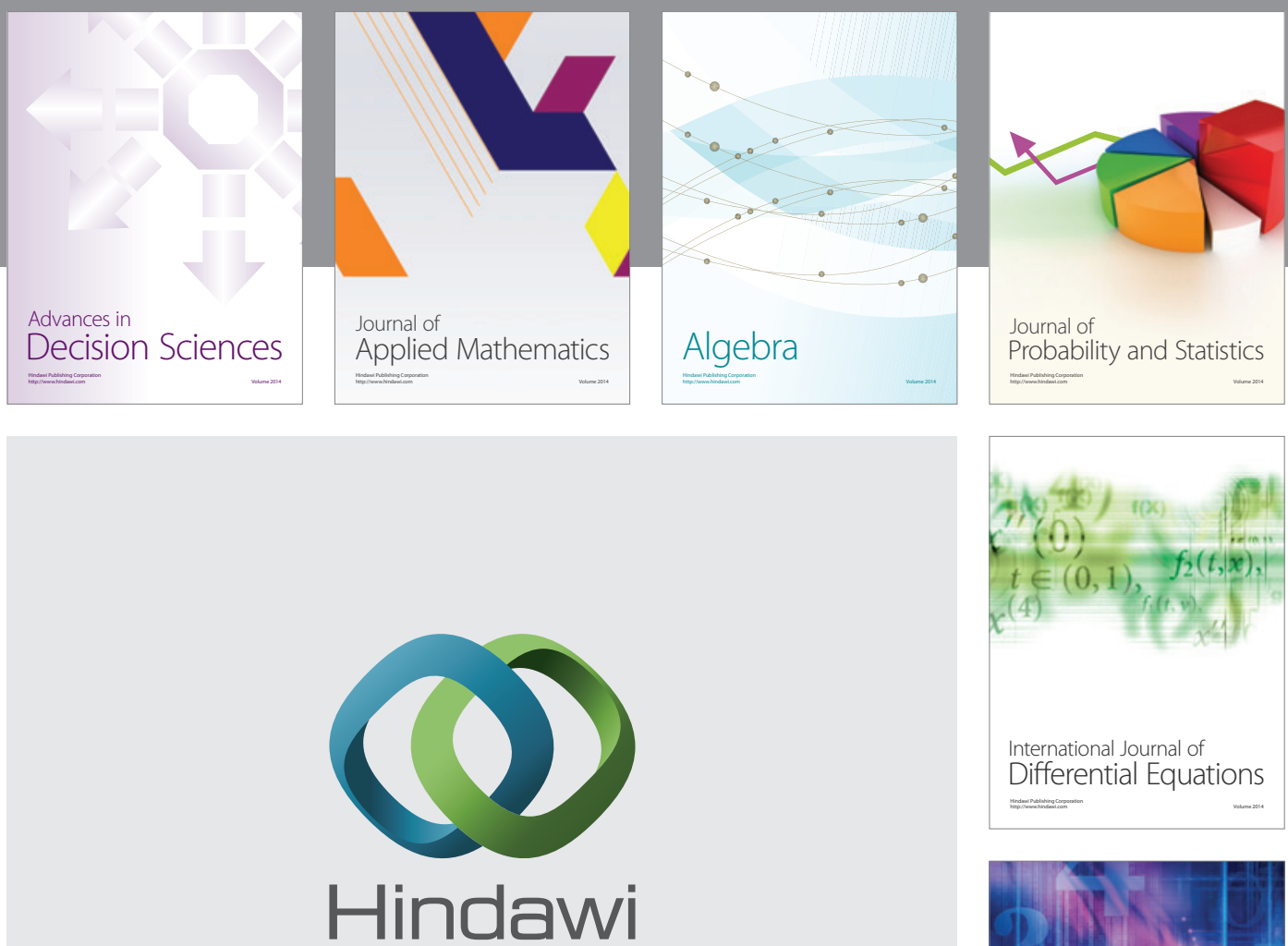

Submit your manuscripts at http://www.hindawi.com
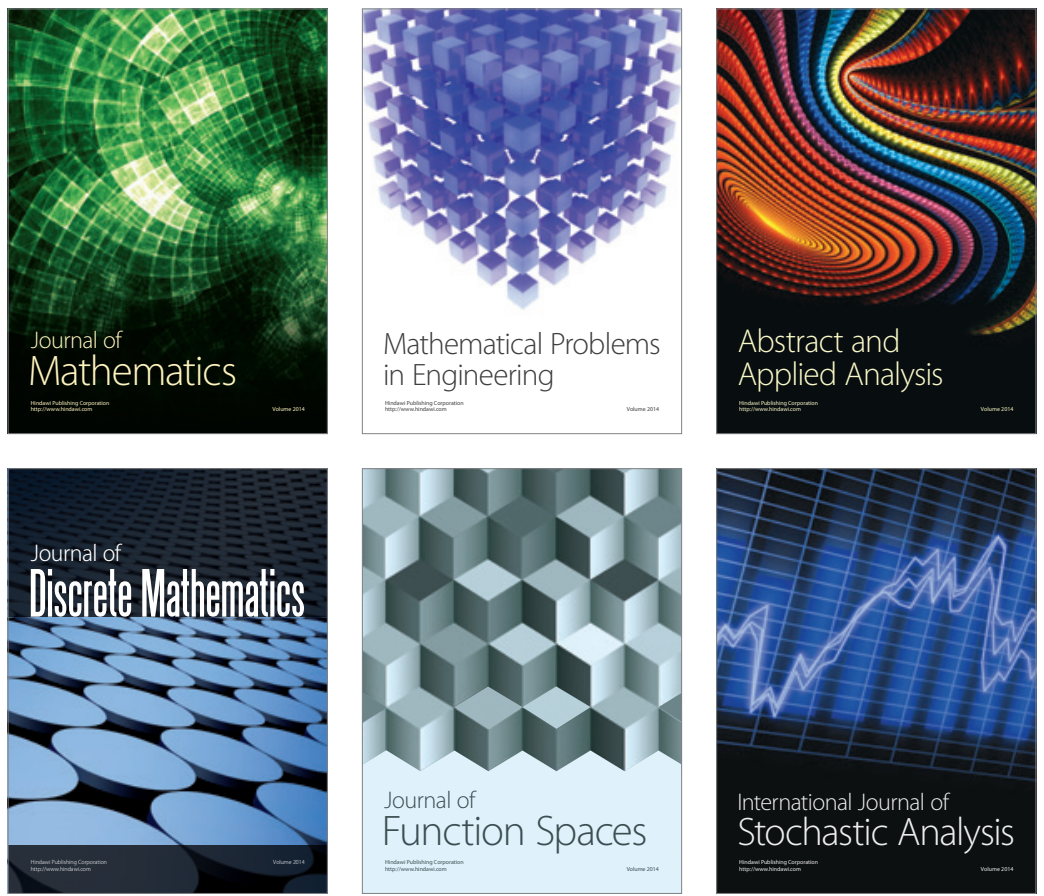

Journal of

Function Spaces

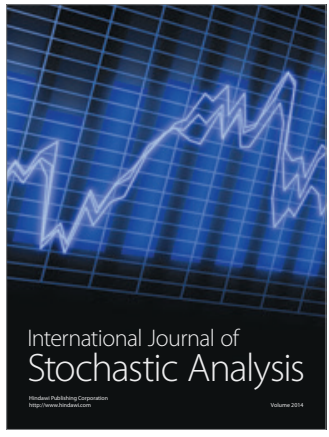

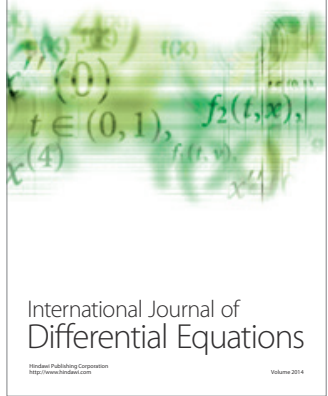
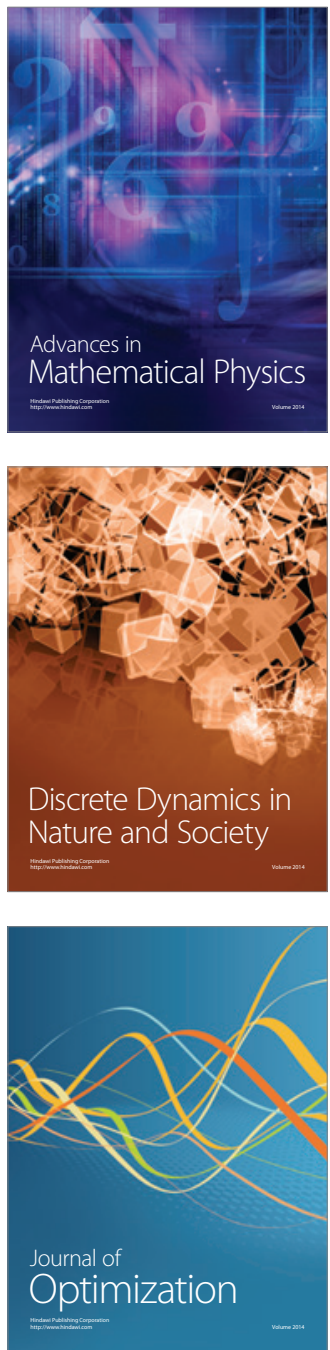